\begin{tabular}{|c|c|c|}
\hline & $\begin{array}{l}\text { COVID-19 period } \\
(2020)\end{array}$ & Pre-COVID-19 period (2019) \\
\hline Number of patients & 51 & 51 \\
\hline Female/Male & $63 \% / 37 \%$ & $45 \% / 55 \%$ \\
\hline Mean age (years) & $63.4(21-87)$ & $64.8(29-86)$ \\
\hline ASA grades & $14 \%(7)$ & $16 \%(8)$ \\
\hline 1 & $37 \%(19)$ & $41 \%(21)$ \\
\hline 2 & $33 \%(17)$ & $31 \%(16)$ \\
\hline 3 & $16 \%(8)$ & $12 \%(4)$ \\
\hline \multicolumn{3}{|l|}{4} \\
\hline Presenting complain & $61 \%(31)$ & $75 \%(38)$ \\
\hline Abdo pain & $43 \%(22)$ & $55 \%(28)$ \\
\hline \multicolumn{3}{|l|}{ Jaundice } \\
\hline Blood test & $107(6-493)$ & $108(3-669)$ \\
\hline Bilirubin (umol/L) & $66(1-206)$ & $64(1-342)$ \\
\hline \multicolumn{3}{|l|}{ CRP (mg/L) } \\
\hline Indications for ERCP & $92 \%(47)$ & $82 \%(42)$ \\
\hline Obstructed CBD & $4 \%(2)$ & $10 \%(5)$ \\
\hline Blocked biliary stent & $4 \%(2)$ & $8 \%(4)$ \\
\hline \multicolumn{3}{|l|}{ Biliary leak } \\
\hline Waiting time for ERCP (days) & $2.5(0-9)$ & $4.6(0-27)$ \\
\hline Length of hospital stay (days) & $20.6(8-31)$ & $21.5(0-175)$ \\
\hline COVID-19 +ve & $7.1(1-43)$ & \\
\hline \multicolumn{3}{|l|}{ COVID-19 -ve } \\
\hline 30-day mortality & $50 \%(2 / 4)$ & $8 \%(4 / 51)$ \\
\hline COVID-19 +ve & $6 \%(3 / 47)$ & \\
\hline \multicolumn{3}{|l|}{ COVID-19 -ve } \\
\hline ERCP success rate & $90 \%(46)$ & $86 \%(44)$ \\
\hline Cannulation rate & $6 \%(3)$ & $16 \%(8)$ \\
\hline Technical failure & $80 \%(16 / 20)$ & $94 \%(16 / 17)$ \\
\hline Complete stone extractions & $88 \%(21 / 24)$ & $85 \%(17 / 20)$ \\
\hline \multicolumn{3}{|l|}{ Extrahepatic strictures stented } \\
\hline ERCP complications & $98 \%(47)$ & $88 \%(45)$ \\
\hline Nil & $4 \%(2)$ & $10 \%(5)$ \\
\hline Post ERCP pancreatitis & - & $2 \%(1)$ \\
\hline Mucosal tear/Bleeding & - & $2 \%(1)$ \\
\hline Biliary sepsis & - & $2 \%(1)$ \\
\hline Desaturation post sedation & & \\
\hline
\end{tabular}

In the COVID-19 positive cohort, two patients passed away due to worsening COVID pneumonitis. One of the patients had COVID-19 prior to ERCP, while the other contracted COVID-19 post-ERCP. Patients who were negative for COVID-19 passed away due to metastatic adenocarcinoma of bile duct, bilateral pleural effusions and atelectasis post cholecystectomy and pulmonary embolism.

In comparison to 2020, the mean length of hospital stays and waiting time for ERCP were slightly longer, at 21.5 days (range, 0-175) and 4.6 days (range, 0-27) respectively.

Conclusion Patients undergoing ERCP who were infected with COVID-19 had longer hospital stay, and higher 30-day mortality compared to those who did not have COVID-19. However, length of hospital stay was shorter in COVID time. There was no statistically significance in the KPI between COVID-time and normal times.

\section{PTU-46 SAFETY AND EFFICACY OF FULLY COVERED METALLIC STENT PLACEMENT FOR PATIENTS WITH PRIMARY SCLEROSING CHOLANGITIS}

1,2Leonardo Henry Eusebi*, ${ }^{3}$ Laura Cristoferi, ${ }^{4}$ Richard Sturgess, ${ }^{1} J o n a t h a n$ Potts, ${ }^{4}$ Laura Dwyer, ${ }^{5}$ Giulia Bonato, ${ }^{2}$ Sinan Sadalla, ${ }^{3}$ Pietro Invernizzi, ${ }^{5}$ Massimiliano Mutignani, ${ }^{1}$ Douglas Thorburn. ${ }^{1}$ Royal Free Hospital, Sheila Sherlock Liver Centre and UCL Institute for Liver and Digestive Health, Royal Free Hospital, London, UK; ${ }^{2}$ Gastroenterology and Endoscopy Unit, IRCCS Azienda Ospedaliero-Universitaria di Bologna, Bologna, Italy; ${ }^{3}$ Department of Medicine and Surgery, University of Milano-Bicocca, Monza, Italy; ${ }^{4}$ Aintree Digestive Diseases Unit, Aintree University Hospital, Liverpool, UK; ${ }^{5}$ Digestive Endoscopy Unit, ASST Niguarda, Milan, Italy

\subsection{6/gutjnl-2021-BSG.119}

Introduction Endoscopic retrograde cholangiopancreatography (ERCP) is the gold standard for the treatment of dominant stricture (DS) in primary sclerosing cholangitis (PSC). Multiple therapeutic options, including dilation and stenting, are available, each with their own benefits and drawbacks. Generally, balloon dilatation is preferred due to lower rates of complications compared to temporary plastic stenting. Anecdotal experience of using fully-covered self-expandable metallic stents (FC-SEMS) in this setting is unfavourable, but larger series are lacking. The aim of this study is to assess safety and efficacy of FC-SEMS in PSC patients with DS.

Methods The endoscopic databases of three European referral centres (London, Liverpool, Milan/Monza) were searched to identify and extract data on patients with PSC diagnosis who underwent ERCP with FC-SEMS placement. Patients with biliary malignancy diagnosed during ERCP or follow-up were excluded.

Results A total of 23 patients were identified from 2010 to 2020. 78\% were males, median age was 52.9 years (range 3282). Indication for FC-SEMS placement were: imaging evidence of DS (43\%), worsening of biochemical cholestasis and jaundice (43\%), acute cholangitis (13\%). Median stricture length was $25 \mathrm{~mm}$ (range 10-70). The length of FC-SEMS deployed were $80 \mathrm{~mm}$ in 8 patients, $60 \mathrm{~mm}$ in $7,40 \mathrm{~mm}$ in 7 and $100 \mathrm{~mm}$ in one patient. In four patients, balloon dilatation was performed before stent placement. In all cases the stent was successfully deployed as planned.

Adverse events (AEs) were observed in 48\%(11/23) of patients, of which $64 \%$ were early ( $<30$ days) (5 acute pancreatitis, 1 biliary bleeding, 1 gallbladder perforation) and $36 \%$ delayed (1 cholangitis and 3 stent migrations).

FC-SEMS were removed/migrated in 18 patients after a median time of 66 days (range 7-462) and 61\% had a DS resolution, while 7 of them required further endoscopic treatment. Three patients died or underwent liver transplant during follow-up.

Conclusions In a multicentre observational study of patients with PSC and DS, FC-SEMS placement while technically successful and resulting in a $>50 \%$ efficacy in DS resolution, was associated with a high rate of treatment-related AEs. We conclude that the use of FC-SEMS in PSC with DS is inadvisable. 